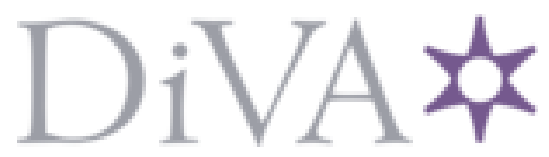

http://www.diva-portal.org

This is the published version of a paper published in Vård $i$ Norden.

Citation for the original published paper (version of record):

Sandh, M., Boström, B. (2012)

Sjuksköterskors uppfattning om smärtbehandling och användning av riktlinjer.

Vård i Norden, 32(106): 44-49

Access to the published version may require subscription.

N.B. When citing this work, cite the original published paper.

Permanent link to this version:

http://urn.kb.se/resolve?urn=urn:nbn:se:hh:diva-20560 


\title{
Sjuksköterskors uppfattning om smärtbehandling och användning av riktlinjer
}

\author{
Marie Sandh MNSc, RN, RNAN, RNT och Barbro Boström PhD, RN, RNIC, RNT
}

\section{NURSES' PERCEPTION OF PAIN MANAGEMENT AND USE OF GUIDELINES}

\begin{abstract}
The aim: The aim was to identify how nurses perceive the performance of pain management and the use of guidelines for pain management. Background: Pain is one of the most common symptoms of illness for which people request health care. Patients in pain ought to be treated quickly and adequately in order to avoid developing a chronic state. Guidelines for effective pain relief are not always implemented in clinical practice.

Method: A questionnaire regarding factors relevant to pain management and guidelines were designed.

Findings: Of the 219 nurses who were invited, 111 (50.7\%) answered the questionnaire. Thirty-one nurses responded that they used guidelines and they administered additional analgesics significantly more often when breakthrough pain occurred compared to nurses responding not using guidelines. Pain assessment is not always performed, 44 nurses agreed completely or partly that pain assessment is performed only when pain in the patient has become a problem. Forty-two nurses agreed completely or partly that there are routines in their department for treating patients with difficult pain issues. The nurses highlighted the importance of collaborating in team and having pain treatment routines. Conclusion: Pain management was perceived to be performed non-systematically and not always adapted to the individual. Guidelines were not always used.
\end{abstract}

KEY WORDS: guidelines, nurse, pain assessment, pain management.

\section{Inledning}

Akut smärta kan utvecklas till långvarig smärta, därför bör patienter med smärta behandlas så tidigt som möjligt under sjukdomsförloppet (1). Förutom lidandet för patienten och anhöriga kan patienters smärta leda till många kontakter med hälso- och sjukvård. Hälso- och sjukvårdspersonal måste därför vara medveten om problemet, inge förtroende och tillit så att patienter med smärta får snabb och korrekt bedömning och lämplig behandling (2).

Strohbuecker $\mathrm{m}$ fl. (3) fann att $63 \%$ av patienter inneliggande på ett universitetssjukhus hade upplevt måttlig till svår smärta under de senaste 24 timmarna. Fyrtioen procent av patienter som hade opererats rapporterade måttlig till svår smärta första postoperativa dygnet (4). I en multinationell studie framkom att $19 \%$ procent av vuxna personer rapporterade långvarig smärta i mer än 6 månader (5). Femtiosex procent av vuxna patienter med en malign sjukdom som ingick $i$ studie av Breivik $\mathrm{m}$ fl. (6) rapporterade måttlig till svår smärta.

Smärta är ett problem för ett stort antal patienter vilket kan bero på att planeringen av smärtbehandling ofta påbörjas sent i sjukdomsförloppet och kan vara otillräcklig (7). Sjuksköterskor informerar inte alltid patienterna om smärtbehandling, trots att de anger att de gör det (8). Dessutom framkom i samma studie att de inte utför smärtbedömning, inte genomför optimal smärtbehandling samt inte heller utvärderar given behandling. I en studie av Marinsek m fl. (9) framkom att $40 \%$ av patienter med akut buksmärta var missnöjda med sin behandling av smärta. Möjliga orsaker till detta kan vara att smärtbedömning inte gjordes på ett korrekt sätt, att utvärdering sällan genomfördes (10), och/eller att läkare (9) och sjuksköterskor (11) uppskattar att patienters smärta är av lägre intensitet än vad patienterna själva upplever. Långa väntetider för att få analgetika är också en orsak till brister i vården av patient med smärta (12). En interventionsstudie av Stalnikowicz $\mathrm{m}$ fl. (11) visade att utbildning av sjuksköterskor minskade diskrepansen mellan patientens och sjuksköterskans bedömning av patienters smärta vilket resulterade $\mathrm{i}$ att antalet patienter som fick implementering av visuell analog skala (VAS) för bedömning och utvärdering av smärta samt införandet av protokoll för smärtbehandling med standardiserade riktlinjer (11). Eftersom det är sjuksköterskor som kontinuerligt har nära kontakt med patienten är sjuksköterskans tidiga insatser nödvändiga (7). Sjuksköterskor måste först förstå patientens smärta, sedan initiera och utvärdera effekten av behandling (13). Sjuksköterskans attityd, kunskap och erfarenhet spelar en betydande roll i detta (14). Trots att sjuksköterskornas kunskaper ökar genom utbildning så har vårdverksamhetens redan etablerade rutiner och strategier stort inflytande på vården. Det kan innebära att om sjuksköterskan inte tycker sig ha makt och möjlighet att ta självständiga beslut för att genomföra förändringar använder de inte sin kunskap som stöd i vården av patient med smärta (15).

American Pain Society har följt upp hur de riktlinjer som de publicerade 1995 har använts i klinisk verksamhet. Efter denna genomgång rekommenderades att det på varje vårdinrättning skall finnas strukturerade riktlinjer för smärtbehandling. Detta innebär att patienternas smärta synliggörs och att smärtbehandlingsstrategier involverar både patienten och närstående (16). Nationella riktlinjer finns tillgängliga som stöd vid behandling av patienter med olika typer av smärtproblematik $(2,17,18)$. I enlighet med dessa rekommenderas att regelbundna utvärderingar genomförs. Vid seminarium med sjuksköterskor inom smärtutbildningar har det ofta framkommit att de nationella riktlinjerna inte alltid varit implementerade i klinisk verksamhet. Ytterligare insatser behövs för att minska gapet mellan teori och klinisk verksamhet (8).

\section{Syfte}

Syftet med studien var att identifiera hur sjuksköterskor uppfattar genomförandet av smärtbehandling och användandet av riktlinjer för smärtbehandling.

\section{Metod}

En beskrivande studie utfördes med kvantitativ metod. 


\section{Urval}

Tvåhundranitton sjuksköterskor uppfyllde inklusionskriterierna för att delta i studien. Inklusionskriterie var att de under de senaste 10 åren genomgått en fristående högskolekurs i smärta och smärtbehandling vid en västsvensk högskola, och därför kunde förväntas ha kunskap om och intresse för smärta och smärtbehandling.

\section{Forskningsetiska överväganden}

Uppgifter om deltagare hämtades från aktuella klasslistor. Enligt Personuppgiftslagen (1998:204) innehåller dessa inga känsliga personuppgifter, som ras, religion, etnisk/politisk/fackföreningstillhörighet (19). De etiska aspekterna är i enlighet med regler och riktlinjer för forskning som involverar människor (20) då informanterna i följebrev informerades om syftet med studien, att deltagandet var frivilligt, samt om svarsanonymitet och sekretess i samband med hanteringen av frågeformulär och data. Etiskt tillstånd till studiens genomförande gavs av lokal etikgrupp.

\section{Datainsamling}

Ett frågeformulär utformades och skickades ut mars 2009. Kodat frågeformulär skickades ut tillsammans med frankerat svarskuvert via post till sjuksköterskornas hemadresser.

En påminnelse skickades ut efter en månad. Åttiosex av 219 sjuksköterskor besvarade inte frågeformuläret trots påminnelse vilket får tolkas som att de antingen inte nåddes av frågeformuläret eller att de inte var intresserade av att svara. Ytterligare 22 sjuksköterskor lämnade ofullständigt ifyllda frågeformulär, där de förklarade att deras nuvarande yrkesroll var sådan att de inte kunde svara på frågorna. Före dataanalys förstördes kodnyckeln.

Totalt kvarstod 111 besvarade frågeformulär.

Förutom demografiska uppgifter, bestod frågeformuläret av tre delar: Del 1 bestod av fyra strukturerade frågor om riktlinjer för smärtbehandling där svaren angavs med ja/nej/vet inte eller antal.

1. Använder ni någon/några kliniska riktlinjer på din avdelning relaterat till patienter med smärta?

Om ja: Hur många riktlinjer om smärta och smärtbehandling används på din avdelning?

1. Är riktlinjen evidensbaserad?

2. Vad tycker du är riktlinjens styrka/styrkor?

- Lätta att förstå

- Lätta att följa

3. Är användningen av senast införda riktlinje utvärderad? (21)

I del 2 ingick 18 påståenden om genomförande av smärtbehandling där svaren angavs på en Likert skala (från instämmer helt till instämmer inte alls). De 18 påståendena utgick ifrån resultatet från en observationsstudie som genomfördes av Brown och McCormack (22) i syfte att avgöra faktorer viktiga för smärtbehandling. Brown och McCormack (22) observerade samspelet mellan patienter och sjuksköterskor vilket resulterade i följande tre teman: Smärtbedömning och behandling; kunskap och strategier för att hantera okontrollerad smärta; organisation av vården. Från beskrivningen av dessa teman samt i enlighet med APS's riktlinjer (16) konstruerades de 18 påståndena som ingick i denna studies frågeformulär. Frågeformulärets del 2 testades på en grupp sjuksköterskor som svarade och gav kommentarer vilket föranledde viss justering avseende de 18 påståendenas ordval. Cronbach's alpha för hela frågeformuläret var 0.48 . Utvecklandet av ett nytt frågeformulär motiverade att en explorativ faktoranalys genomfördes. Denna resulterade i 3 faktorer. Faktor 1 representerade smärtbehandlingsrutiner (loadings $0.37-0.72$, Cronbach's alpha coefficient 0.54), faktor 2 representerade kontinuitet (loadings 0.65-0.78, Cronbach's alpha coefficient 0.63 ), faktor 3 representerade organisation (loadings $0.40-0.70$, Cronbach's alpha coefficient 0.73 ).

Del 3 innehöll två öppna frågor för att ge sjuksköterskorna en möjlighet att med egna ord uttrycka sin uppfattning om hur smärtbehandling genomförs.

1. Vad fungerar i nuvarande smärtbehandlingsrutin och varför?

2. Vad fungerar inte i nuvarande smärtbehandlingsrutin och varför?
Dataanalys

Kvantitativa data har bearbetats i SPSS 16.0 (Statistical Package för Social Science) och redovisas med beskrivande statistik. Mann-Whitney U-test användes för att beskriva skillnader mellan hälso- och sjukvårdspersonal som arbetar i öppen och sluten vård och mellan de som använde riktlinjerna och de som inte använde riktlinjer. Statistisk signifikans nivå sattes till $\mathrm{p}<0.01$. De öppna frågornas svar har analyserats med manifest innehållsanalys (23). Det innebär att de svar som 79 sjuksköterskor gav och som omfattade en text på 2980 ord har kategoriserats utifrån det som direkt uttrycktes i texten.

\section{Resultat}

Etthundraelva sjuksköterskor $(50.7 \%)$ besvarade frågeformuläret. Genomsnittliga antalet yrkesverksamma år som sjuksköterska var 18 år. Inom öppenvården arbetade 53 sjuksköterskor och inom slutenvården 56 (bortfall $n=2$ ). Öppenvårdssjuksköterskorna arbetade inom hemtjänst, inklusive palliativ vård i hemmet. Sjuksköterskorna inom slutenvård arbetade inom medicin, kirurgi, palliativ vård, anestesi eller akutmottagning. Trettioen sjuksköterskor uppgav att det fanns smärtombud i den organisationen, där de arbetar. Elva hade blivit smärtombud efter att de genomgått kursen i smärta och smärtbehandling.

Trettioen av 93 (33.3\%) sjuksköterskor svarade att de använde riktlinjer, antal riktlinjer varierade mellan 1 och 6 . Ingen statistiskt signifikant skillnad observerades i användningen av riktlinjer inom sluten eller öppen vård.

Tjugotre av $26(88.5 \%)$ uppgav att de riktlinjer de hade var lätta att förstå och 21 av 26 (80.8\%) att riktlinjerna var lätta att följa. Tio av 27 (37\%) uppgav att riktlinjerna var evidensbaserade. Sex av $26(23.1 \%)$ uppgav att de nyligen införda riktlinjer hade utvärderats, medan 12 av 26 (46.2\%) visste inte om de riktlinjer som de använde var utvärderade.

De som använde riktlinjer angav statistiskt signifikant oftare att patienter vid smärtgenombrott fick analgetikum jämfört med de sjuksköterskor som inte använde riktlinjer $(\mathrm{p}=.008)$.

Åtta $(8.2 \%)$ svarade att de helt samtyckte med att det fanns rutiner att behandla patienter med problematisk smärtproblematik. Tolv (12.5\%) samtyckte helt med att smärtbedömning gjordes först när smärtan är ett problem hos patienten. Fyrtioåtta (48\%) samtyckte helt med att smärta alltid dokumenterades i patientjournalen (tabell I).

Innehållsanalysen av de öppna frågornas svar resulterade i 6 kategorier vilka redovisas med direkta citat i tabell II

\section{Diskussion}

Etthundratrettiotre (60.7\%) sjuksköterskor besvarade frågeformuläret. Av dessa svarade 22 endast på demografiska data, samt förklarade att de inte längre var kliniskt verksamma sjuksköterskor. Svarsfrekvensen var därmed $50.7 \%$, vilket kan ses som studiens begränsning och minskar resultatets generaliserbarhet. Eftersom användandet av de 18 påståendena i del 2 av frågeformuläret utvecklats från resultatet i en observationsstudie (22) testades validiteten genom att en faktoranalys genomfördes. Denna resulterade i de tre faktorerna behandlingsrutiner, kontinuitet och organisation som kan uppfattas som relevanta eftersom de finns med som innehåll i svaren på de öppna frågorna (tabell II). Faktorerna som var resultatet av faktoranalysen överensstämmer även med forskningsresultat som visar att sjuksköterskor inte alltid har en smärtbehandlingsstrategi (8) och att långa väntetider påverkar kvalitén på behandlingen (12). Det kan ses som ett organisatoriskt problem. Boström $\mathrm{m}$ fl. (7) fann att kontinuiten var en viktig faktor vid vård av patient med smärta. Reliabiliteten på del $2 \mathrm{i}$ frågeformuläret (tabell I) var låg (Cronbach's alpha 0.48). Detta kan bero på att påståendena var för generella, att sjuksköterskorna skulle svara övergripande utifrån vad de uppfattar att sjuksköterskor gör och inte specifikt vad de själva gör samt att det interna bortfallet varierade i del 2 av frågeformuläret mellan 11 och 52 .

Det mest anmärkningsvärda resultatet var att sjuksköterskorna angav att smärtbedömning inte alltid skedde, att patientens smärtbehandling inte alltid individanpassades, att patienterna inte alltid fick behandling vid smärtgenombrott (tabell I) samt att endast 31 sjukskö- 
Tabell I. Sjuksköterskornas uppfattning av smärtbehandling

Totalt antal informanter $\mathrm{n}=111$. Skillnaden mellan totalt antal och individuellt antal avser internt bortfall.

\begin{tabular}{|c|c|c|c|c|}
\hline Påstående & $\begin{array}{l}\text { Samtycker } \\
\text { helt } \\
\text { n (\%) }\end{array}$ & $\begin{array}{l}\text { Samtycker } \\
\text { delvis } \\
\text { n (\%) }\end{array}$ & $\begin{array}{l}\text { Samtycker } \\
\text { delvis inte } \\
\text { n (\%) }\end{array}$ & $\begin{array}{l}\text { Samtycker } \\
\text { inte } \\
\text { n (\%) }\end{array}$ \\
\hline $\begin{array}{l}\text { Smärtbedömning sker endast vid medicinska ronder } \\
(\mathrm{n}=94)\end{array}$ & & $7(7.4)$ & $18(19.1)$ & $69(73.4)$ \\
\hline $\begin{array}{l}\text { Farmakologisk smärtbehandling ordineras endast } \\
\text { vid ronder }(n=93)\end{array}$ & $3(3.2)$ & $9(9.7)$ & 19 (20.4) & $62(66.7)$ \\
\hline $\begin{array}{l}\text { Patienterna tillfrågas alltid om sitt behov av } \\
\text { smärtbehandling }(\mathrm{n}=100)\end{array}$ & $41(41)$ & 39 (39) & 18 (18) & $2(2)$ \\
\hline $\begin{array}{l}\text { Patienterna är delaktiga i beslut om sin smärtbehandling } \\
(\mathrm{n}=100)\end{array}$ & $30(30)$ & $48(48)$ & $18(18)$ & $4(4)$ \\
\hline $\begin{array}{l}\text { Jag förklarar alltid för mina patienter om deras smärta } \\
\text { och smärtbehandling }(\mathrm{n}=102)\end{array}$ & $55(53.9)$ & $41(40.2)$ & $6(5.9)$ & \\
\hline $\begin{array}{l}\text { Icke farmakologiska metoder ingår alltid som del av } \\
\text { smärtbehandlingen }(\mathrm{n}=102)\end{array}$ & $20(19.6)$ & $48(47.1)$ & 17 (16.7) & 17 (16.7) \\
\hline $\begin{array}{l}\text { Det finns rutiner på avdelningen för att behandla } \\
\text { patienter med problematisk smärtproblematik }(n=97)\end{array}$ & $8(8.2)$ & $34(35.1)$ & $24(24.7)$ & $31(32)$ \\
\hline $\begin{array}{l}\text { På vår avdelning är det rutin att alltid ge analgetika } \\
\text { peroralt ( } \mathrm{n}=99)\end{array}$ & $17(17.2)$ & $23(23.2)$ & 18 (18.2) & $41(4.41)$ \\
\hline $\begin{array}{l}\text { Jag har alltid möjlighet att individanpassa tidpunkten } \\
\text { för analgetikaadministrering }(\mathrm{n}=99)\end{array}$ & $52(52.5)$ & $33(33.3)$ & $6(6.1)$ & $8(8.1)$ \\
\hline $\begin{array}{l}\text { Om en patient har smärtgenombrott ges alltid extra } \\
\text { dos av analgetika }(n=99)\end{array}$ & 55 (55.6) & $29(29.3)$ & $10(10.1)$ & $5(5.1)$ \\
\hline $\begin{array}{l}\text { Smärtbedömning görs först när smärtan hos patienten } \\
\text { är ett problem }(n=96)\end{array}$ & $12(12.5)$ & $32(33.3)$ & $20(20.8)$ & $32(33.3)$ \\
\hline $\begin{array}{l}\text { Jag diskuterar med smärtombud endast om det uppstår } \\
\text { problem i smärtbehandling av en patient }(\mathrm{n}=63)\end{array}$ & $7(11.1)$ & $9(14.3)$ & 15 (23.8) & $32(50.8)$ \\
\hline Jag använder de råd jag får av smärtombudet $(\mathrm{n}=59)$ & $15(25.4)$ & $15(25.4)$ & $4(6.8)$ & $25(42.4)$ \\
\hline $\begin{array}{l}\text { Sjuksköterskor och läkare samarbetar omkring patient } \\
\text { med smärta }(\mathrm{n}=99)\end{array}$ & $51(51.5)$ & $42(42.4)$ & $4(4)$ & $2(2)$ \\
\hline $\begin{array}{l}\text { Den vård patienten med smärta får präglas av kontinuitet } \\
(\mathrm{n}=94)\end{array}$ & $26(27.7)$ & $45(47.9)$ & $16(17)$ & $7(7.4)$ \\
\hline $\begin{array}{l}\text { Smärtbehandlingen blir ineffektiv på grund av att } \\
\text { vi sjuksköterskor blir avbrutna av andra arbetsuppgifter } \\
(\mathrm{n}=96)\end{array}$ & $12(12.5)$ & $41(42.7)$ & $13(13.5)$ & $30(31.2)$ \\
\hline $\begin{array}{l}\text { Sjuksköterskorna rapporterar alltid muntligt till kollega } \\
\text { om patient har smärta }(n=97)\end{array}$ & $42(43.3)$ & $36(37.1)$ & $7(7.2)$ & $12(12.4)$ \\
\hline $\begin{array}{l}\text { Sjuksköterskorna dokumenterar alltid patientens smärta } \\
\text { i journalen }(n=100)\end{array}$ & $48(48)$ & $36(36)$ & 12 (12) & $3(3)$ \\
\hline
\end{tabular}




\section{Tabell II. Uppfattningar av smärtbehandling uttryckta av sjuksköterskorna.}

\section{Vad fungerar i nuvarande smärtbehandlingsrutin och varför?}

Kategorier med citat

Teamarbete

Sjuksköterskor och läkare diskuterar alltid patientens problem med smärta och behandlingsstrategier

- Engagerade och kompetenta läkare lyssnar på sjuksköterskan synpunkter

\section{Engagemang}

- Vi ger information, stöd och lyssnar till patienten och utvärderar behandling

- Vi visar att vi tar patientens smärta på allvar

Behandlingsstrategier

- Att vi har bra generella direktiv innebär att patienterna fär snabb och bra smärtbehandling

- Vi har skrivit riktlinjer som ger oss stora möjligheter att ge god smärtbehandling efter smärtbedömning
Vad fungerar inte i nuvarande smärtbehandlingsrutin och varför?

Kategorier med citat

Kunskap

- Okunnighet om riktlinjerna är anledningen till att det inte fungerar

- Min erfarenhet är att många läkare har bristande kunskaper om smärta

- Min uppfattning är att patienterna inte förstår vikten av behandlingen av smärtan

Attityd

- Även vår inställning till smärta kan ha en negativ effekt på smärtlindring och läkare är ibland rädda för att ordinera adekvata doser

Behandlingsstrategier

-Visuell analog skala används nästan aldrig, inte heller några smärtbedömningsinstrument där patienten själv kan beskriva smärtans karaktär och lokalisation

- Jag tror de generella direktiven är dåligt utnyttjade terskor uppgav att de använde riktlinjer. Fyrtiofyra sjuksköterskor samtyckte helt eller delvis med att smärtbedömning gjordes först när smärtan hos patienten var ett problem, trots att flera sjuksköterskor på de öppna frågorna svarade att smärtbedömning är en förutsättning för att smärtbehandlingen skall bli bra. Sjuksköterskan är ansvarig för genomförandet av vårdprocessen och sjuksköterskans agerande är därmed en förutsättning för god smärtbehandling (13). Resultatet visade att det fanns brister i bedömningen av patienternas smärta, ett faktum som även observerats i andra studier $(10,24)$. Kaasalainen $m$ fl. (25) hävdade att denna brist i smärtbedömning kan vara en följd av begränsad tillgång till smärtbedömningsinstrument. Dihle m fl. (8) visade att sjuksköterskor bedömer patientens smärta utifrån vad de själva upplever istället för att använda smärtbedömningsinstrument. Att använda smärtbedömningsinstrument ger patient och sjuksköterska ett gemensamt språk (14), vilket kan förbättra kommunikationen i diskussionen om patientens smärta och resultera $\mathrm{i}$ att patienter får individuellt anpassad behandling. I samband med smärtbedömning är det viktigt att sjuksköterskan ställer direkta frågor om patientens smärta för att på bästa sätt avgöra vilka analgetika som är mest effektiva (26) samt att frågor ställs utifrån smärtans samtliga dimensioner (7). Om sjuksköterskan bara observerar patientens icke-verbala tecken på smärta, kan det vara otillräckligt som underlag för att uppnå god smärtlindring (8).

Knappt $11 \%$ av sjuksköterskorna svarade att de samtyckte helt eller delvis till påståendet att farmakologisk smärtlindring bara ordineras under ronder. Om ordination av analgetika begränsas till att ske endast under ronder så kan det medföra svårigheter att individualisera smärtbehandlingen. I resultatet framkom även att endast 31 av 111 sjuksköterskor angav att de använde riktlinjer. Om dessutom generella direktiv saknas och patienten kan få vänta på behandling blir det brister i vårdkvalitéen (12). Resultatet visade att endast drygt hälften (55\%) av sjuksköterskorna samtyckte helt med påståendet att patienter som hade genombrottssmärta alltid gavs extra dos av analgetika. Det fanns dock en skillnad mellan de sjuksköterskor som använde riktlinjerna och de som inte använde riktlinjer. De sjuksköterskor som sa att de använde riktlinjer angav i statistiskt signifikant högre utsträckning att de samtyckte helt med att de gav extra doser av anal- getika vid genombrottssmärta. Att inte behandla genombrottsmärta medför ökat lidande för patienten (27) varför det hade varit önskvärt att samtliga sjuksköterskor i studien hade samtyckt helt med detta påstående. Detta visar även att effekten av att använda riktlinjer kan vara gynnsam när sjuksköterskan kan stödja sina åtgärder på riktlinjer med generella direktiv. Detta överensstämmer med Muntlin m fl. (28) som visade att om sjuksköterskor på en akutmottagning hade riktlinjer i form av generella direktiv gavs analgetika till patienter med akut buksmärta mer frekvent. Mindre än hälften av sjuksköterskorna, 10 av 27, ansåg att riktlinjerna var evidensbaserade. Detta kan ses som en brist eftersom riktlinjer bör vara evidensbaserad, alltså baserade på forskning, klinisk erfarenhet och patientens upplevelse (29). Endast sex uttryckte att de nyligen införda riktlinjerna på deras avdelning hade utvärderats. Även detta kan ses som en brist eftersom riktlinjer måste utvärderas för att säkerställa att de är uppdaterade och funktionella. Utvärdering är en mycket viktig del i implementeringen av nya riktlinjer $(16,30)$.

Enligt 31 sjuksköterskor fanns inte rutiner på deras avdelningar för att kunna behandla patienter med smärtproblematik. Detta är ytterligare en brist som skulle kunna förhindras om riktlinjer funnits som inkluderat behandling av patient med smärtproblematik.

Endast 30 sjuksköterskor samtyckte till att patienten deltog i sin smärtbehandling. Eftersom sjuksköterskor, i samband med att de genomför smärtbedömning, behandling och utvärdering, har ett utmärkt tillfälle att informera och förklara för patienten borde samtliga sjuksköterskor samtyckt. Det kan då leda till att patienten upplever delaktighet och kontroll över sin situation. Patienten kanske då inte uppvisar det missnöje med smärtbehandlingen som framkom i en studie av Marinsek m fl. (9). Om sjuksköterskan genomför en smärtbedömning i samspel med patienten kan patienten däremot uppleva tillit och uppleva att kommunikationen med sjuksköterskan är bra (7). Warren Stomberg $\mathrm{m}$ fl. (28) visade att om preoperativ information ges minskar patientens smärta och patienttillfredsställelsen ökar. Om patienten är oinformerad kan detta ge en otrygghet som skapar osäkerhet vilket i sin tur leder till att patienten inte informerar sjuksköterskan om sin smärta (29). Willson (30) visade att sjuksköterskor hellre följer gängse rutiner när de ger patienten analgetika än diskutera med pati- 
enten om dennes behov. Enligt Manias m fl. (31) är det viktigt att sjuksköterskan är lyhörd för patientens signaler om smärta.

I resultatet framkom att sjuksköterskorna inte alltid rapporterade muntligt till någon kollega om att patient hade smärta och att sjuksköterskorna inte alltid dokumenterade patientens smärta $\mathrm{i}$ journalen vilket sjuksköterskorna, i de öppna frågorna, angav som en förutsättning för god smärtbehandling. Wickström Enes $m$ fl. (35) fann att tjugo procent av sjuksköterskorna svarade att de sällan eller aldrig dokumenterar smärtintensitet. Att dokumentera genomförda åtgärder såsom genomförd bedömning och behandling är en lagstadgad skyldighet (36) varför samtliga sjuksköterskor borde ha svarat att de samtycker helt på dessa två påståenden. En förutsättning för god smärtbehandling är att behandlingen utvärderas och dokumenteras. Wickström Ene $\mathrm{m}$ fl. (35) visade att om patients smärtvärdering med hjälp av VAS dokumenterades av sjuksköterskan ökade patientens chans att få opioider som postoperativ smärtbehandling.

Av svaren på de öppna frågorna (tabell II) framkom att när patientfall diskuterades sjuksköterskor emellan eller mellan sjuksköterskor och läkare upplevde sjuksköterskorna att smärtbehandlingen fungerade bättre. Det handlar om att sjuksköterskorna och läkarna samarbetar mot gemensamt mål med utbyte av varandras unika kunskaper (37). Betydelsen av att arbeta i team framfördes även i svaren på de öppna frågorna. Innan teamarbete fungerar kan det ta tid men i förlängningen frigörs tid eftersom behandling kan effektiviseras. Om planering av smärtbehandling inte är med från början av sjukdomsförloppet kan detta innebära en otillfredsställande smärtbehandling som orsakar olidlig smärta för patienten och blir tidskrävande för vårdgivarna (7). De öppna frågorna visade att attityden bland vårdpersonal mot smärta kan ha en negativ effekt på smärtlindring. Detta bekräftas av Chang m fl. (38) som visade att sjuksköterskans attityd påverkade om och i vilken dos cancerpatienter fick opioid. Det kan även finnas en rädsla hos sjuksköterskor att ge patienter opioider (25) samt en ovilja att administrera opioider av rädsla för biverkningar och för att patienterna skall utveckla beroende (24).

Om klinisk erfarenhet inte utnyttjas och om verksamheten inte är öppen för förändringar, kommer arbetet med att implementera nya rutiner i vården hämmas (30). Enbart riktlinjer är dock ett otillräckligt verktyg för att förändra vårdens rutiner. Engagemang för patienter hos personal och administratörer samt att alla ska arbeta mot samma mål är viktiga faktorer för att säkerställa att förändringar initieras (39). Resultatet visade att sjuksköterskorna ansåg att det är viktigt att både läkare och sjuksköterskor har kunskap och erfarenhet. Detta överensstämmer med Tsai m fl. (40), som visade att ju mer kunskap sjuksköterskor har om smärta, desto färre hinder för smärtbehandling upplevdes. Smärtbedömning och smärtbehandling förbättras efter utbildning (11), men samtidigt fann Twycross (41) att sjuksköterskor inte använder de teoretiska kunskaper de har. Detta kan möjligen bero på att sjuksköterskor inte känner sig ha mandat att använda denna kunskap.

Kaasalainenen $\mathrm{m}$ fl. (25) fann att sjuksköterskor ansåg att de hade stöd i behandlingen av patient med smärta om de använder smärtbedömningsinstrument och om sjuksköterskor, läkare och farmaceuter samverkar. Även utbildning och förtroendeingivande samarbete med läkare ansågs vara stödjande funktioner.

\section{Slutsats}

Resultaten visade att riktlinjer sällan användes. Brister beskrevs i smärtbedömning och behandling. Då patienter med smärta oavsett orsak fortfarande uppvisar en icke acceptabel smärta trots tillgång till riktlinjer och smärtbehandlingsmetoder är det värdefullt att det inrättas stödfunktioner för sjuksköterskorna så att användandet av riktlinjer ökas. Ett behov föreligger också att utveckla lokala riktlinjer som implementeras och kontinuerligt utvärderas.

\section{Tack}

Vi tackar alla informanter i studien.
Godkjent for publisering 3.09.2012

Marie Sandh MNSc, RN, RNAN, RNT och Barbro Boström PhD, RN, RNIC, RNT

Högskolan Halmstad, Sektionen för Hälsa och Samhälle.

Korrespondens till: Marie Sandh, Sektionen för Hälsa och Samhälle, Högskolan Halmstad, Box 823 SE-301 18 Halmstad.

Tlf: +4635 167461. E-post: marie.sandh@hh.se

\section{Referenser}

1. Woolf CJ, Salter MW. Neuronal plasticity: increasing the gain in pain. Science. 2000;288(5472):1765-1769.

2. Statens beredning för medicinsk utvärdering [SBU]. Metoder för behandling av långvarig smärta. En systematisk litteraturöversikt, 177/1 . Stockholm: Statens beredning för medicinsk utvärdering; 2006.

3. Strohbuecker B, Mayer H, Evers GC, Sabatowski R. Pain prevalence in hospitalized patients in a German university teaching hospital. Pain Symptom Management. 2005;29(5):498-506.

4. Sommer M, de Rijke JM, van Kleef M, Kessels AG, Peters ML. The prevalence of postoperative pain in a sample of 1490 surgical inpatients. European Journal of Anaesthesiology. 2008;25:267-274

5. Breivik H, Collett B, Ventafridda V, Cohen R, Gallacher D. Survey of chronic pain in Europe: Prevalence, impact on daily life and treatment. European Journal of Pain. 2006;10:287-333.

6. Breivik H, Cherney N, Colett B, de Conno F, Filbet M, Cohen R, Dow L. Cancer-related pain: a pan-European survey of prevalence, treatment and patient attitudes. Annals of Oncology. 2009;20(8):1420-1433.

7. Boström B, Sandh M, Lundberg D, Fridlund B. Cancer-related pain in palliative care: patients' perceptions of pain management. Journal of Advanced Nursing. 2003;45(4):410-4198.

8. Dihle A, Bjölseth G, Helseth S. The gap between saying and doing in postoperative pain management. Journal of Clinical Nursing. 2006;15:469-479.

9. Marinsek M, Kovacic D, Versnik D, Parasuh M, Golez S, Podbregar M. Analgesic treatment and predictors of satisfaction with analgesia in patients with acute undifferentiated abdominal pain. European Journal of Pain. 2007;11:773-778.

10. Todd KH, Ducharme J, Choiniere M, Crandall CS, Fosnandt DE, Homel P, Tanab P, PEMI study group. Pain in the Emergency Department: Results of the Pain and Emergency Medicine Initiative (PEMI) Multicenter Study. Journal of Pain 2007;8(6):460-466.

11. Stalnikowicz R, Mahamid R, Kaspi S, Brezis M. Undertreatment of acute pain in the emergency department: a challenge. International Journal for Quality Health Care. 2005;17(2):173-176.

12. Lee G, Smith S, Jennings N. Low acuity abdominal pain in the emergency department: still a long wait. International Emergency Nursing. 2008;16:94-100.

13. Holley S, McMillan SC, Hagan SJ, Palacios P, Rosenberg D. Pain Resource Nurses: Believing the Patients Believing in Themselves. Oncology Nursing forum. 2005;32(4):843-848.

14. Layman Young J, Horton FM, Davidhizar R. Nursing attitudes and beliefs in pain assessment and management Journal of Advanced Nursing. 2006;53(4):412-421.

15. Wilson B. (2007). Nurses'knowledge of pain. Journal of Clinical Nursing. 2007;16:1012-1020.

16. Gordon DB, Dahl JL, Miaskowski C, McCarberg B, Todd KH, Paice JA, Lipman AG, Bookbinder M, Sanders SH, Turk DC, Carr DB. American pain society recommendations for improving the quality of acute and cancer pain management: American Pain Society Quality of Care Task Force Archives of internal medicine. 2005;165:1574-1580.

17. Svensk sjuksköterskeförening och Spri. Cancerrelaterad smärta. Riktlinjer, patientundervisning och komplementär smärtbehandling. Omvårdnad, 7. Stockholm: Spri förlag, 1999.

18. Svenska Läkarsällskapet, Gothia AB. Behandling av postoperative smärta riktlinjer och kvalitetsindikatorer. Svensk medicin, 70. Stockholm: Svenska Läkarsällskapet \& Gothia AB, 2001. 
19. Socialdepartementet. Svensk författningssamling (SFS) Personuppgiftslagen (1998:204). (reviderad 2010:1969).

http://www.riksdagen.se/webbnav/index.aspx?nid=3911\&bet=1998:204

20. Vetenskapsrådet och Uppsala universitet. Codex Regler och Riktlinjer för forskning. Uppsala: Vetenskapsrådet och Uppsala universitet. http://www.codex.vr.se/forskarensetik.shtml.

21. Bahtsevani C, Willman A, Khalaf A, Östman M. Developing an instrument for evaluating of clinical practice guidelines: a test-retest study. Journal of Evaluation in Clinical Practice. 2008;4:839-846.

22. Brown D, McCormack B. Determining factors that have an impact upon effective evidence-based pain management with older people following colorectal surgery: an ethnographic study. Journal of Clinical Nursing. 2006;15:1287-1298.

23. Graneheim UH, Lundman B. Qualitative content analysis in nursing research: concepts, procedures and measures to achieve trustworthiness. Nurse Education Today. 2004;24(2):105-112.

24. Jeon YS, Kim HK, Cleeland CS, Wang XS. Clinicians' practice and attitudes toward cancer pain management in Korea. Supportive Care in Cancer. 2006;15:463-469.

25. Kaasalainen S, DiCenso A, Donald FC, Staples E. Optimizing the Role of the Nurse Practitioner to Improve Pain Management in Long-Term Care. Canadian Journal of Nursing Research. 2007;39(2):14-31.

26. Schafheutle EI, Cantrill JA, Noyce PR. The nature of informal pain questioning by nurse - a barrier to post-operative pain management? Pharmacy World \& Science. 2004;26:12-17.

27. Hagen NA, Biondo P, Stiles C. Assessment and management of breakthrough pain in cancer patients: current approaches and emerging research. Current pain and headache reports. 2008;12(4):241-248.

28. Muntlin $\AA$, Carlsson M, Gunningberg, L. Barriers to Change Hindering Quality Improvement: The Reality of Emergency Care Journal of Emergency Nursing. 2010;36(4):317-323.

29. Rycroft-Malone J. The PARIHS Framework - A framework for guiding the implementation of evidence based practice. Journal of Nursing Care Quality. 2004;19(4):297-304.

30. Rycroft-Malone J, Harvey G, Seers K, Kitson A, McCormack B, Titchen, A. An exploration of the factors that influence the implementation of evidence into practice. Journal of Clinical Nursing. 2004;13:913-924.
31. Warrén Stomberg M, Wickstrom K, Joelsson H, Sjostrom B, Haljamae H. Postoperative pain management on surgical wards--do quality assurance strategiesresult in long-term effects on staff member attitudes and clinical outcomes? Pain Management Nursing. 2003;4(1):11-22.

32. McDonald DD, McNulty J, Erickson K, Weiskopf, C. Communicating pain and painmanagement needs after surgery. Applied Nursing Research. 2000;13(2):70-75.

33. Willson H. Factors affecting the administration of analgesia to patients following repair of a fractured hip. Journal of Advanced Nursing 2000;31(5):1145-1154.

34. Manias E, Bucknall T, Botti M. Nurses' strategies for managing pain in the postoperative setting. Pain Management Nursing. 2005;6(1):18-29.

35. Wickström Ene K, Nordberg G, Berg I, Gaston Johansson F, Sjöström B. Postoperative pain management the influence of surgical ward nurses. Journal of Cinical Nursing. 2008;17:2042-2050.

36. Socialdepartementet. Svensk författningssamling (SFS) Patientdatalagen (2008:355). http://www.riksdagen.se/webbnav/index.aspx?nid=3911\&bet=2008:355

37. Carr DB, Reines HD, Schaffer J, Polomano RC, Lande S. The impact of technology on the analgesic gap and quality of acute pain management. Regional Anesthesia and Pain Medicine. 2005;30(3):286-291.

38. Chang Y J, Yun Y H, Park SM, Lee SW, Park HA, Ro YJ, Huh BY. Nurses' willingness to maximize opioid analgesia for severe cancer pain and its predictor. Supportive Care in Cancer. 2005;13(9):743-751.

39. Greenhalgh T, Robert G, Macfarlane F, Kyriakidou O. Diffusion of innovations in service organizations: systematic review and recommendations. Milbank Quarterly. 2004;82(4):581-629.

40. Tsai FC, Tsai YF, Chien CC, Lin CC. Emergency nurses' knowledge of perceived barriers in pain management in Taiwan. Journal of Clinical Nursing. 2007;16:2088-2095

41. Twycross A. Educating nurses about pain management: the way forward. Journal of Clinical Nursing. 2002;11:705-714 